\title{
ORIGINAL
}

\section{The risk and clinical outcome of candidemia depending on underlying malignancy}

\author{
Olivier Lortholary ${ }^{1,2^{*}}$, Charlotte Renaudat ${ }^{1}$, Karine Sitbon ${ }^{1}$, Marie Desnos-Ollivier ${ }^{1}$, Stéphane Bretagne ${ }^{1,3}$, \\ Françoise Dromer ${ }^{1}$ and The French Mycoses Study Group
}

(c) 2017 The Author(s). This article is an open access publication

\begin{abstract}
Purpose: To assess the risk factors and outcomes associated with fungemia caused by the six most commonly occurring Candida species in patients with and without malignancies.

Methods: Analysis of the episodes of fungemia due to common Candida species in adults, based on an active hospital-based surveillance program (Paris area, France, 2002 to 2014).

Results: Of the 3417 patients (3666 isolates), 1164 (34.1\%) had a solid tumor (45.7\% digestive tract) and 586 (17.1\%) a hematological malignancy (41.8\% lymphoma, 33.5\% acute leukemia). The hematology patients were significantly younger, more often pre-exposed to antifungals, more often infected by C. tropicalis, C. krusei, or C. kefyr, and more often treated in the first instance with an echinocandin. Compared with inpatients who were not in ICU at the time of fungemia, those in ICU were less frequently infected by C. parapsilosis $(p<0.02)$, had more recent surgery $(p<0.03)$, and died more frequently before day 8 and day $30(p<0.0001)$. An increase in crude mortality over time in ICU was observed only in oncology patients $(p<0.04)$. For all patients, lack of prescription of antifungals despite knowledge of positive blood culture increased the risk of death. The odds of being infected by a given Candida species compared with C. albicans were uneven regarding age, gender, type of malignancy, hospitalization in ICU, central venous catheter, HIV status, intravenous drug addiction, and previous exposure to antifungal drugs. Compared with C. albicans, C. glabrata $(\mathrm{OR}=0.69$ [0.54-0.89]) and C. parapsilosis $(\mathrm{OR}=0.49$ [0.35-0.67]) were associated with a decreased risk of death by day 8 and day 30 .
\end{abstract}

Conclusion: The clinical context of underlying malignancy and hospitalization in ICU may be relevant to the initial management of candidemia.

Keywords: Candida, Echinocandins, Fluconazole, Hematological malignancy, Cancer, ICU, Non-albicans species

\footnotetext{
*Correspondence: olivier.lortholary@pasteur.fr

${ }^{1}$ Institut Pasteur, Molecular Mycology Unit, French National Reference Center for Invasive Mycoses and Antifungals, CNRS URA3012, 25, rue du Dr. Roux, 75724 Paris Cedex 15, France

Full author information is available at the end of the article
}

The members of the French Mycoses Study Group are listed in the "Acknowledgements" section and ESM 5.

Take-home message: The type of underlying malignancy (solid vs hematological) and hospitalization in vs outside ICU impact differentially on fungemia by different species of Candida.

\section{Introduction}

Candidemia currently represent up to $10 \%$ of nosocomial bloodstream infections [1-3] with associated mortality, increased length of stay and cost [4]. It is therefore a public health concern everywhere [5]. Among the risk factors, hematological malignancies and solid tumors represent a large proportion [6, 7]. Many changes have occurred over the last decade with the increased incidence of fungemia due to Candida glabrata at least in some settings $[8,9]$, the availability of echinocandins

\section{实


[10-12] and new broad-spectrum triazoles prophylaxis in hematology, the implementation of management guidelines [13, 14], and better suspicion/awareness of clinicians. Whether or not all these changes impact the characteristics and outcome of candidemia among adults with malignancy needs to be further investigated. Several retrospective monocentric studies described the local epidemiology of candidemia among patients with malignancy [15-17] and only two recent prospective studies concerned cancer patients $[18,19]$. No study has ever analyzed the characteristics and outcome of infection in patients with solid tumor or hematological malignancy developing candidemia and the impact of their hospitalization in intensive care unit (ICU) [20].

We launched in 2002 a large prospective hospital-based surveillance program on patients developing candidemia in the Paris area and recently reported the characteristics of patients hospitalized in ICU [9] and of those who developed fungemia due to rare yeasts [21]. The goal of the present study was to characterize over more than a decade Candida spp. distribution and prognostic factors according to underlying malignancy and ICU hospitalization. We also determined if the context associated with non-albicans candidemia was suggestive enough to help the clinician with the first therapeutic choice.

\section{Materials and methods}

\section{Population studied and isolates characterization}

A sustainable active surveillance program on yeast fungemia (YEASTS program) was implemented with participation of 26 short-stay university hospitals in the Paris area. All blood cultures positive with yeasts were notified, with data completed on a standardized form, on a secured website. All isolates were sent to the French National Reference Center for Invasive Mycoses and Antifungals (NRCMA). There, purity and identification were assessed [22] and in vitro susceptibility testing performed according to the EUCAST procedure [23]. The current analysis concerns the incident episodes of candidemia recorded in patients aged at least 15 years old between October 2002 and December 2014, and due to C. albicans, C. glabrata, C. tropicalis, C. parapsilosis complex that includes C. metapsilosis and C. orthopsilosis (hereafter named C. parapsilosis), C. krusei (current name Pichia kudriavzevii), and C. kefyr (current name Kluyveromyces marxianus). Single and mixed (>1 species) infections were considered.

\section{Definitions}

The date of candidemia was that of blood sampling (day 0). Patients were assigned to one of three groups: hematological malignancy, solid tumor ("oncology"), or "no malignancy". Surgery and antifungal preexposure (whatever dosage and duration) occurring within 30 days prior to candidemia were recorded. First-line antifungal therapy was analyzed only for patients for whom the positivity of the blood culture was known before death and was categorized into four groups: "fluconazole", "echinocandins", "other treatments" (all other antifungals and drug combinations), and "no antifungals". Antifungal drug resistance was defined as minimum inhibitory concentration (MIC) $\geq 8 \mathrm{mg} / \mathrm{L}$ [24] for fluconazole and MIC $>0.25 \mathrm{mg} / \mathrm{L}$ for caspofungin [25].

\section{Statistical analysis}

Univariate analysis was based on Chi2 or Fisher's exact test when needed for discrete variables. Kruskal-Wallis test was used to compare means for groups with unequal variances. Chi2 test for trends was used to determine trends over time. In order to identify risks factors for fungemia due to non-albicans Candida species, a multinomial regression analysis was performed that analyzed parameters suggesting infection by a given species or by multiple species based on information available at the time of the positive blood culture. The most common species, i.e., $C$. albicans, was used as reference to avoid blurring the picture by changing the reference for each species. All baseline variables representing pre-existing conditions before fungemia were first included in a full model and only risk factors significantly associated $(p<0.05)$ with at least one species were kept in the final model adjusted on the year of fungemia.

To identify risk factors associated with death (crude death rate at day 30 or day 8), backward stepwise logistic regression models adjusted for the hospital and the year of inclusion were used for all patients and the three groups. First, non-colinear covariates with a $p$ value under 0.25 in the univariate analysis were simultaneously entered into the models and then removed one by one until all of the covariates remaining in the reduced models had a $p$ value under 0.05 . Survivals were compared by the logrank test. Data were analyzed using Stata Statistical Software (version 12.0; College Station, TX).

\section{Results}

Characteristics of patients with candidemia according to the presence of malignancy and/or hospitalization in ICU

A total of 3417 adults were diagnosed with candidemia, for a total of 3572 episodes (Fig. 1). Almost half (47.2\%) were hospitalized in ICU (Table 1). The 586 hematological malignancies consisted mainly of lymphoma (41.8\%) and acute leukemia (AL, 33.5\%). Allogeneic hematopoietic cell transplantation (HSCT, 10.9\%) and graft versus host disease $(5.1 \%)$ were recorded in hematology. The 1164 solid tumors involved the digestive (45.7\%), 


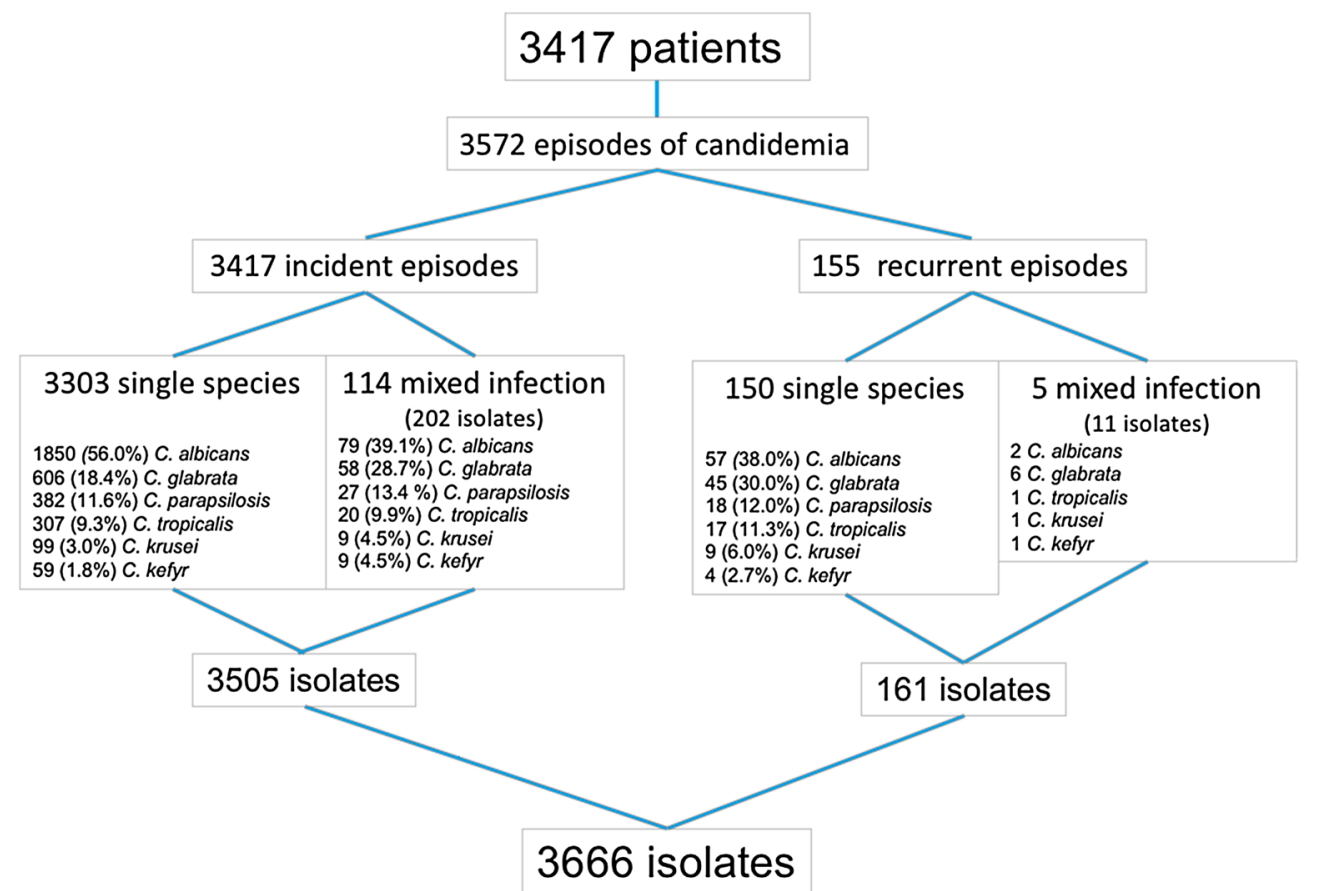

Fig. 1 Flow chart showing the incident and recurrent episodes of fungemia due to the six more common Candida species recorded during the YEASTS program, Paris, France (10/01/2002-12/31/2014)

genital $(12.3 \%)$, or urinary $(8.9 \%)$ tract, or the ear, nose, and throat area (11.0\%). Almost half (46.5\%) of the 1667 patients with no malignancy had recent surgery involving the digestive tract $(364 / 775,46.9 \%)$ or cardiovascular invasive procedures $(200 / 775,25.8 \%)$, and the majority had a central venous catheter (64.6\%). Hospitalization in ICU was significatively more frequent in patients with no malignancy $(1080 / 1667,64.8 \%)$ compared to oncology $(335 / 1164,28.8 \%)$ or hematology $(199 / 586,34.0 \%)$ patients $(p<0.0001)$. Recent surgery was overall significantly more frequently recorded in ICU vs. outside ICU (Tables 1, S1), especially for patients with lymphoma (Table S2) and those with digestive tumors (Table S3).

The most frequent first-line treatment was fluconazole $(51.2 \%)$ or echinocandin $(29.7 \%)$ with major differences according to the underlying disease and stay in ICU (Tables 1, S1-S3). Prescriptions were similar in vs. outside ICU for hematology patients but not in others. The proportion of patients who received no antifungal drug was similar in the three groups whether in or outside ICU.

\section{Species distribution and impact of ICU hospitalization and underlying disease}

Of the 3666 isolates recovered, 737 (20.1\%) were considered resistant to fluconazole. The vast majority (89\%) was composed of C. glabrata $(76.1 \%$ of them) and
C. krusei (all), and a few isolates of C. parapsilosis (7.5\%), C. tropicalis $(8.4 \%)$, and C. albicans (0.8\%). A caspofungin MIC $>0.25 \mu \mathrm{g} / \mathrm{mL}$ concerned 211 (6.5\%) isolates including $41.5 \%$ of the C. parapsilosis, and few C. albicans and C. tropicalis (0.7\% each), C. glabrata (2.5\%), C. krusei (2.6\%), and C. kefyr (1.7\%). The proportion of patients preexposed to antifungals was significantly higher in hematology (Table 1), especially those with AL (Table S2), with no impact of ICU hospitalization. In oncology, the proportion of breakthrough infections was low and similar to that recorded in patients with no malignancy. However, oncology patients had twice as many breakthrough infections when in ICU compared to outside ICU, whereas the figures did not change for patients with no malignancy (Table S1).

Mixed infection accounted for 3.3\% of all episodes, less frequently in hematology patients (Table 1$)$. Species involved differed significantly $(p<0.001)$ between single and mixed infection, the latter involving predominantly C. albicans and C. glabrata (Fig. 1). The interval between sampling and blood culture positivity varied significantly with almost $40 \%$ of the cultures recovered after more than 3 days for C. glabrata compared to more than $40 \%$ of the cultures positive in less than $24 \mathrm{~h}$ for $C$. krusei, $C$. kefyr, and C. tropicalis ( $p<0.0001$, Fig. 3).

For single infections, species distribution varied significantly with the underlying condition and stay in 
ICU (Tables 1, S1-S3). C. albicans was the predominant species in all settings, but its proportion was significantly lower in hematology patients compared to those with solid tumor or no malignancy. This decrease was observed specifically in patients with AL, especially in ICU where C. albicans accounted for only $29.4 \%$ of the species compared to more than $50 \%$ in patients with other hematological malignancies including lymphoma. Candida tropicalis was almost as frequent as C. albicans in ICU patients with AL, and almost twice as much as in the other hematology patients outside ICU. ICU patients with lymphoma had very few $C$. parapsilosis infections compared to those outside ICU, or to AL patients (Table S2), as did ICU patients with non-digestive tumors compared to those with digestive tumors, or to all oncology patients outside ICU (Table S3). Overall, C. parapsilosis was less frequent in ICU than outside ICU in both hematology and oncology patients (Table 1). Candida glabrata was more frequent in oncology than in hematology patients and those with no malignancy, and even more in ICU. The proportion of C. glabrata was significantly higher outside ICU in oncology patients with digestive tumor than in those without, whereas it was similar in ICU. Finally, C. kefyr was more frequent in hematology patients, whether in ICU or not (Table 1).

The multinomial analysis uncovered independent factors that were associated with a given species (Table 2). Relative to patients infected by C. albicans, those infected by $C$. glabrata were older, had more frequent digestive tumors, and were less likely to have HIV infection. Those infected by C. krusei had more frequent nondigestive tumors, $\mathrm{AL}$, or lymphoma, and less frequent surgery. Those infected by $C$. parapsilosis were more often younger and male, had a central venous catheter, and were less likely to be hospitalized in ICU or to have HIV infection. Those with $C$. tropicalis were more often male, more likely suffering from AL or other hematological malignancies. Those with C. kefyr were more likely to have AL and be 65-79 years old. Multiple species infection were more likely in the context of intravenous drug addiction, with a trend to be more likely in patients with central venous catheter and non-digestive solid tumors. Finally, preexposure to fluconazole was independently associated with infection by C. glabrata and C. krusei while preexposure to caspofungin predisposed to infection by C. glabrata, C. krusei, and C. parapsilosis.

\section{Outcome}

Survival was significantly decreased in ICU (Fig. 2, logrank test $p<0.0001)$. The crude death rate at day 30 was overall increased in ICU and this was related to an increased rate in patients with no malignancy (Tables 1 , S1). The crude day 30 death rate was similar when

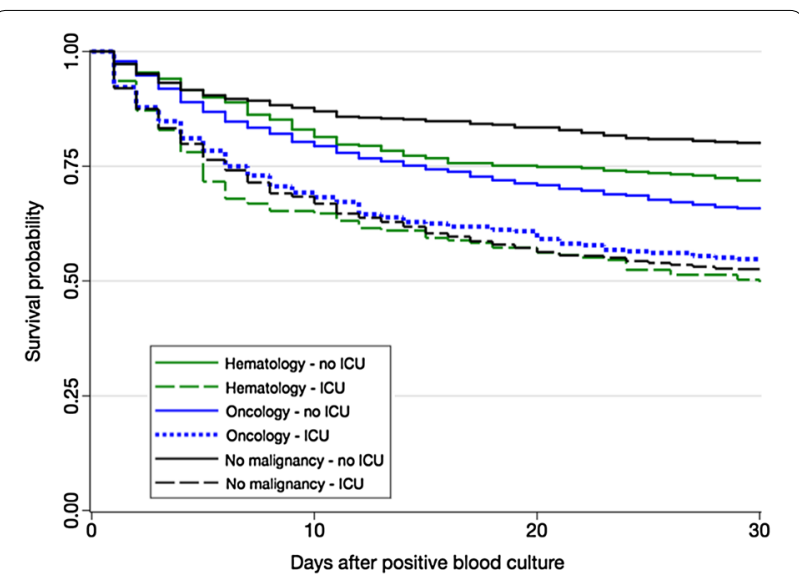

Fig. 2 Survival rate after candidemia according to the hospitalization in ICU or not in patients with solid tumor, hematological malignancy, or no malignancy. Kaplan-Meier curves. YEASTS program, Paris area (October 2002-December 2014)

hospitalized in ICU and not influenced by the underlying malignancy (Tables S2-S3). The crude death rate at day 30 outside ICU was significantly increased in oncology patients compared to others, and this was related to a significantly increase in delayed death rate (Table 1).

We then analyzed the independent risk factors for death following fungemia due to single species according to its timing and to the groups (Tables 3, S4). For the entire population and each group, the lack of antifungal drug prescription and hospitalization in ICU (the latter not for early death in hematology and oncology patients) were identified as risk factors for death. The odds of death at day 30 was increased in oncology patients compared to patients with no malignancy. Compared to C. albicans, C. glabrata and C. parapsilosis were associated with a decreased risk of day 8 and day 30 deaths (all patients, oncology patients), while only $C$. parapsilosis was in patients with no malignancy (day 8 and day 30 ). Of note, the risk of early death was $3.07(p=0.052)$ for $C$. kefyr infection in oncology patients. The species had no influence on the risk of death for hematology patients. Recent surgery was associated with a decreased risk of day 8 (all patients) and day 30 death (all patients, oncology, no malignancy), while preexposure to echinocandins was associated with an increased risk of death in patients with no malignancy.

\section{Trends over a decade}

There was no significative trend over time for the major characteristics of the patients, including the proportion of older patients, lymphoma, and HSCT among the hematological malignancies, or of digestive origin among the solid tumors. Preexposure to antifungals did 
Table 1 Comparison of major characteristics according to hospitalization outside $(n=1803)$ or in $(n=1614)$ intensive care unit (ICU) in three major populations (hematological malignancy, solid tumor, or no malignancy) of adult patients with incident candidemia due to common species (YEASTS program, Paris area, Oct 2002-Dec 2014)

\begin{tabular}{|c|c|c|c|c|c|c|c|c|}
\hline & \multicolumn{4}{|l|}{ Outside ICU } & \multicolumn{4}{|l|}{ In ICU } \\
\hline & $\begin{array}{l}\text { Hematology } \\
(n=387)\end{array}$ & $\begin{array}{l}\text { Oncology } \\
(n=829)\end{array}$ & $\begin{array}{l}\text { No malignancy } \\
(n=587)\end{array}$ & $p$ & $\begin{array}{l}\text { Hematology } \\
(n=199)\end{array}$ & $\begin{array}{l}\text { Oncology } \\
\text { (335) }\end{array}$ & $\begin{array}{l}\text { No malignancy } \\
(n=1080)\end{array}$ & $p$ \\
\hline Age (mean $\pm S D$ ) & $54 \pm 18$ & $63 \pm 14$ & $60 \pm 21$ & 0.0001 & $57 \pm 16$ & $64 \pm 13$ & $59 \pm 17$ & 0.0001 \\
\hline Male gender & 217 (56.1\%) & 496 (59.8\%) & 347 (59.1\%) & 0.455 & $133(56.8 \%)$ & 209 (62.4\%) & $652(60.4 \%)$ & 0.214 \\
\hline $\begin{array}{l}\text { Recent surgery } \\
\quad(<30 \text { days })\end{array}$ & $20(5.2 \%)$ & 295 (35.6\%) & 246 (41.9\%) & $<0.0001$ & $20(10.1 \%)$ & 194 (57.9\%) & 529 (49.0\%) & $<0.0001$ \\
\hline $\begin{array}{l}\text { Central venous } \\
\text { catheter }\end{array}$ & $329(85.0 \%)$ & $657(79.3 \%)$ & $269(45.8 \%)$ & $<0.0001$ & 165 (82.9\%) & $268(80.0 \%)$ & $808(74.8 \%)$ & 0.014 \\
\hline $\begin{array}{l}\text { Previous antifungal } \\
\text { treatment }\end{array}$ & 72 (18.6\%) & $39(4.7 \%)$ & $41(7.0 \%)$ & $<0.0001$ & $49(24.6 \%)$ & $32(9.6 \%)$ & 96 (8.9\%) & $<0.0001$ \\
\hline Fluconazole & $22(5.7 \%)$ & $30(3.6 \%)$ & $25(4.3 \%)$ & 0.252 & $19(9.6 \%)$ & $20(6.0 \%)$ & $58(5.4 \%)$ & 0.075 \\
\hline Echinocandins & $30(7.8 \%)$ & $6(0.7 \%)$ & $8(1.4 \%)$ & $<0.0001$ & $17(8.5 \%)$ & $7(2.1 \%)$ & $22(2.0 \%)$ & $<0.0001$ \\
\hline \multicolumn{9}{|l|}{ Type of infection } \\
\hline Single pathogen & $(n=382)$ & $(n=789)$ & $(n=568)$ & & $(n=195)$ & $(n=321)$ & $(n=1048)$ & \\
\hline C. albicans & 187 (49.0\%) & 444 (56.3\%) & 339 (59.7\%) & 0.005 & 97 (49.7\%) & 179 (55.8\%) & 604 (57.6\%) & 0.122 \\
\hline C. glabrata & $42(11.0 \%)$ & $156(19.8 \%)$ & 97 (17.1\%) & 0.001 & 32 (16.4\%) & 79 (24.6\%) & 200 (19.1\%) & 0.041 \\
\hline C. parapsilosis & 64 (16.8\%) & 91 (11.5\%) & 78 (13.7\%) & 0.047 & $14(7.2 \%)$ & $22(6.9 \%)$ & $113(10.8 \%)$ & 0.054 \\
\hline C. tropicalis & 54 (14.1\%) & $62(7.9 \%)$ & 44 (7.8\%) & 0.001 & 34 (17.4\%) & $20(6.2 \%)$ & 93 (8.9\%) & $<0.0001$ \\
\hline C. krusei & $20(5.2 \%)$ & $24(3.0 \%)$ & $7(1.2 \%)$ & 0.002 & $10(5.1 \%)$ & $14(4.4 \%)$ & $24(2.3 \%)$ & 0.035 \\
\hline C. kefyr & 15 (9.9\%) & 12 (1.5\%) & $3(0.5 \%)$ & $<0.0001$ & $8(4.1 \%)$ & $7(2.2 \%)$ & $14(1.3 \%)$ & 0.028 \\
\hline Multiple pathogens & $5(1.3 \%)$ & $40(4.8 \%)$ & $19(3.2 \%)$ & 0.007 & $4(2.0 \%)$ & $14(4.2 \%)$ & $32(3.0 \%)$ & 0.341 \\
\hline $\begin{array}{l}\text { First-line treatment } \\
\text { after diagnosis }\end{array}$ & $(n=348)$ & $(n=709)$ & $(n=275)$ & & $(n=111)$ & $(n=265)$ & $(n=809)$ & \\
\hline Fluconazole & 104 (29.9\%) & 460 (64.9\%) & 275 (58.9\%) & $<0.0001$ & 45 (28.5\%) & $121(49.6 \%)$ & $411(50.8 \%)$ & $<0.0001$ \\
\hline Echinocandins & 144 (41.4\%) & 135 (19.0\%) & $107(22.9 \%)$ & $<0.0001$ & 67 (42.4\%) & $86(35.3 \%)$ & $273(33.8 \%)$ & 0.114 \\
\hline $\begin{array}{l}\text { Others (including } \\
\text { combination) }\end{array}$ & 74 (21.3\%) & $52(7.3 \%)$ & $53(11.4 \%)$ & $<0.0001$ & $36(22.8 \%)$ & 27 (11.1\%) & 75 (9.3\%) & $<0.0001$ \\
\hline No treatment & $26(4.5 \%)$ & $62(8.7 \%)$ & $32(6.9 \%)$ & 0.475 & $10(6.3 \%)$ & $10(4.1 \%)$ & $50(6.2 \%)$ & 0.451 \\
\hline \multicolumn{9}{|l|}{ Death rate ${ }^{a}$} \\
\hline $\begin{array}{l}\text { Overall death at } \\
\text { day } 30\end{array}$ & 111/377(29.4\%) & $\begin{array}{r}265 / 760 \\
(34.9 \%)\end{array}$ & $\begin{array}{c}119 / 529 \\
(22.5 \%)\end{array}$ & $<0.0001$ & 98/191 (51.3\%) & 150/312 (48.1\%) & 524/1036 (50.6\%) & 0.699 \\
\hline $\begin{array}{l}\text { Early death } \\
(<\text { day } 8)^{b}\end{array}$ & $57 / 376(15.2 \%)$ & 130/757 (17.2\%) & $68 / 525(13.0 \%)$ & 0.119 & $65 / 190(34.2 \%)$ & $94 / 310(30.3 \%)$ & $334 / 1030$ (32.4\%) & 0.645 \\
\hline $\begin{array}{l}\text { Late death } \\
\text { (between days } \\
\text { 8-30) }\end{array}$ & $53 / 376(14.1 \%)$ & $\begin{array}{l}132 / 757 \\
(17.4 \%)\end{array}$ & 47/525 (9.0\%) & $<0.0001$ & $32 / 190(16.8 \%)$ & $54 / 310(17.4 \%)$ & 184/1030 (17.9\%) & 0.937 \\
\hline
\end{tabular}

Data are mean \pm SD or $n / N(\%)$-denominator is specified when data are missing

a Denominator represents the number of patients for whom the positivity of the blood culture was known before death and/or for whom the information about treatment was recorded

b Precise date of death was missing, preventing definition of "early death" or "late death" in the corresponding patients

not vary for fluconazole, whereas preexposure to echinocandins significantly increased in the global population, and in the three groups, but only in ICU (chi2 for trends, $p=0.015$ for hematology, $p=0.022$ for oncology, and $p=0.0395$ for no malignancy). The proportion of C. parapsilosis significantly decreased in patients with solid tumor (from $15.4 \%$ to $5.6 \%, p=0.026$ ). There was no increase in the proportion of resistant isolates among those of species intrinsically susceptible to fluconazole or caspofungin. After candidemia diagnosis, fluconazole first-line prescription decreased (from 59.8\% to $29.8 \%, p<0.0001$ ), while echinocandin first-line therapy increased (from $4.9 \%$ to $57.6 \%, p<0.0001$ ), with the same trends observed when analyzing specifically the three groups. Finally, there was no trend in crude mortality among hematology patients in or outside ICU. There 


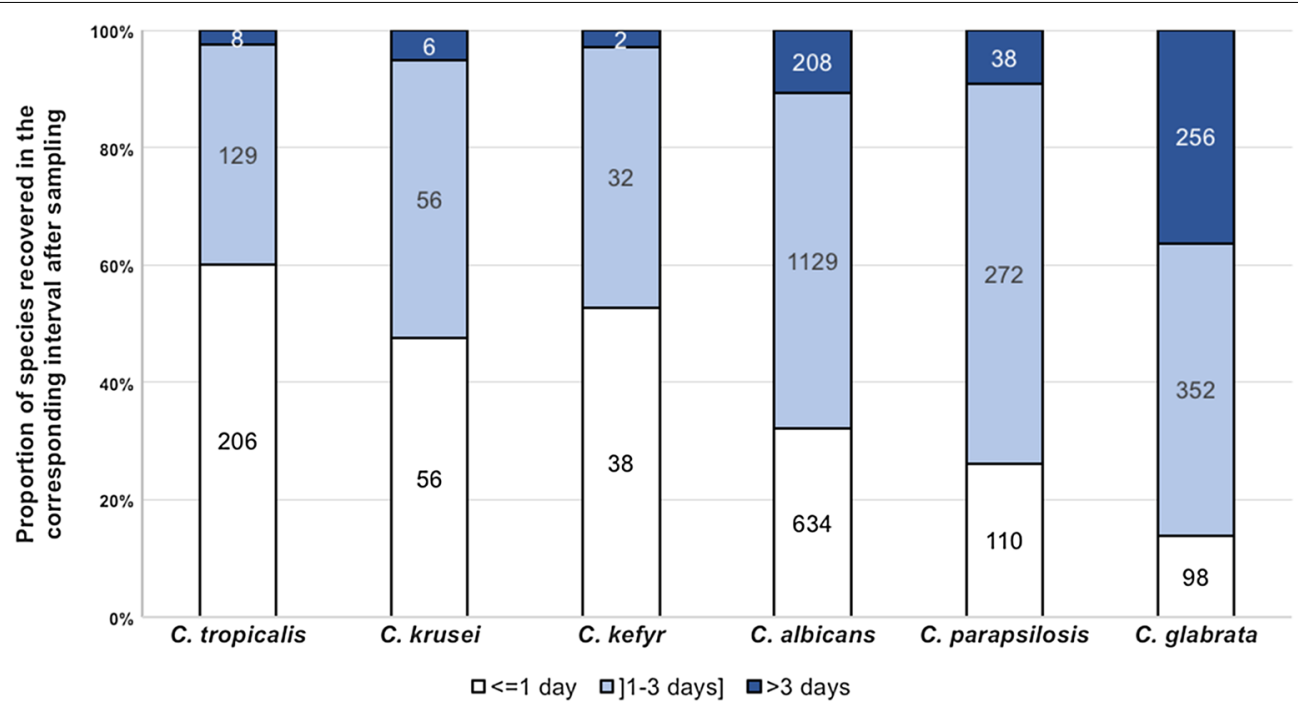

Fig. 3 Proportion of each species identified in blood cultures found positive less than 24 h, between 1 and 3 days, and more than 3 days after sampling

was a significant trend towards an increase in day 30 (from $18.2 \%$ to $58.3 \%, p=0.0321$ ) and day 8 (from $9.1 \%$ to $41.7 \%, p=0.0047$ ) deaths among oncology patients in ICU, but not outside ICU, and no trend observed among patients with no malignancy.

\section{Discussion}

We used a prospective multicentric hospital-based surveillance program to analyze whether fungemia due to common Candida species differed depending on the underlying disease and what the impact of ICU hospitalization was. Malignancies currently represent approximately $35 \%$ of underlying diseases during candidemia [7, $26]$ lower than what we found (50.5\%). Candidemia represents approximately $30 \%$ of invasive fungal infections in hematology patients [27], mostly in those with AL [28, 29], whereas a predominance of lymphoma was observed here. The incidence of fungemia (90\% candidemia) is reported at $0.23 \% / 145,030$ admissions in 13 European cancer centers [19] and at $0.14 \%$ in nine hematology centers in Greece [18]. In France, an incidence of 2.5/100,000 population/year was reported with significant increase in the hematology and oncology populations [30].

Overall, a higher proportion of C. tropicalis and C. krusei [7, 31-34], C. kefyr [35], and sometimes C. glabrata [32] fungemia is found in hematology, and multi-species episodes are more frequent in oncology [36]. We and others evidenced the impact of preexposure to antifungals on the distribution of Candida species [22, 37, 38], and that duration of fluconazole exposure influences the risk of C. krusei fungemia in hematology [6, 39]. We observed less C. albicans in hematology, that being related to AL patients. Less C. parapsilosis was observed in ICU, which may reflect more drastic hygiene procedures there. These observations were reinforced by those of the multinomial analysis demonstrating independent factors of being infected by a given Candida species.

Crude mortality at day 30 in hematology patients was comparable to former series $[18,40]$. It was higher for oncology patients than for the other two groups outside ICU, and hospitalization in ICU increased mortality. One may speculate that the better early outcome found in patients with AL outside ICU may be related to early empiric antifungal therapy administered during prolonged febrile neutropenia. However, crude mortality in ICU was not influenced by underlying disease, which suggests that organ failure(s) was (were) probably the major determinant(s) of outcome. The worrisome trend in the evolution of candidemia mortality that we reported in ICU [9] is explained by the outcome in oncology patients, suggesting that specific actions should now be focused on this currently rising population. One can hypothesize that the oncology patients sent to ICU now have more severe illnesses. Using the multivariate analysis, we showed that the independent risk factors for death varied depending on the underlying disease. In hematology patients, the species recovered from blood culture did not influence death nor did the type of hematological malignancy, while the age and hospitalization in ICU did. In oncology patients and in patients with no malignancy, other factors influenced survival.

Being infected by C. parapsilosis or C. glabrata was independently associated with a more favorable outcome. In the multinomial analysis, we found that, in comparison 
Table 2 Risk factors for fungemia due to C. glabrata, C. parapsilosis, C. tropicalis, C. krusei, C. kefyr or multiple species in reference to fungemia due to $C$. albicans $(n=1850)$, multivariate multinomial regression analysis (YEASTS program, Paris area, October 2002-December 2014)

\begin{tabular}{|c|c|c|c|c|c|c|c|c|c|}
\hline & \multicolumn{3}{|c|}{ C. glabrata } & \multicolumn{3}{|c|}{ C. krusei } & \multicolumn{3}{|c|}{ C. parapsilosis } \\
\hline & OR & $95 \% \mathrm{Cl}$ & $p$ & OR & $95 \% \mathrm{Cl}$ & $p$ & OR & $95 \% \mathrm{Cl}$ & $p$ \\
\hline Male sex & 0.86 & $0.71-1.04$ & 0.116 & 1.37 & $0.88-2.14$ & 0.163 & 1.58 & $1.24-2.01$ & $<0.0001$ \\
\hline \multicolumn{10}{|l|}{ Age (years) } \\
\hline$<45$ & 1 & & & 1 & & & 1 & & \\
\hline $45-64$ & 1.25 & $0.92-1.70$ & 0.146 & 0.86 & $0.09-1.53$ & 0.615 & 0.67 & $0.49-0.90$ & 0.007 \\
\hline $65-79$ & 1.34 & $0.98-1.84$ & 0.064 & 0.68 & $0.36-1.29$ & 0.238 & 0.46 & $0.33-0.65$ & $<0.0001$ \\
\hline$\geq 80$ & 1.77 & $1.23-2.56$ & 0.002 & 0.69 & $0.28-1.74$ & 0.436 & 0.42 & $0.26-0.67$ & $<0.0001$ \\
\hline ICU & 1.22 & $0.99-1.50$ & 0.060 & 1.43 & $0.91-2.27$ & 0.122 & 0.64 & $0.49-0.82$ & 0.001 \\
\hline Recent surgery (<30 days) & 0.94 & $0.76-1.14$ & 0.516 & 0.55 & $0.33-0.92$ & 0.024 & 0.89 & $0.69-1.15$ & 0.387 \\
\hline \multicolumn{10}{|l|}{ Underlying disease } \\
\hline No malignancy & 1 & & & 1 & & & 1 & & \\
\hline Digestive tumor & 1.62 & $1.24-2.12$ & $<0.0001$ & 1.48 & $0.70-3.12$ & 0.304 & 0.79 & $0.54-1.14$ & 0.206 \\
\hline Other solid tumor & 1.01 & $0.76-1.33$ & 0.948 & 2.45 & $1.35-4.45$ & 0.003 & 0.75 & $0.53-1.06$ & 0.101 \\
\hline Acute leukemia & 1.11 & $0.66-1.88$ & 0.682 & 3.36 & $1.49-7.55$ & 0.003 & 1.22 & $0.74-2.00$ & 0.440 \\
\hline Lymphoma & 0.81 & $0.54-1.24$ & 0.338 & 2.28 & $1.09-4.76$ & 0.028 & 0.66 & $0.41-1.07$ & 0.095 \\
\hline Other hematological malignancy & 0.60 & $0.34-1.06$ & 0.079 & 1.48 & $0.53-4.15$ & 0.456 & 0.78 & $0.43-1.39$ & 0.394 \\
\hline Central venous catheter & 0.88 & $0.71-1.09$ & 0.244 & 1.30 & $0.75-2.26$ & 0.344 & 1.44 & $1.08-1.92$ & 0.012 \\
\hline HIV infection & 0.55 & $0.31-0.99$ & 0.046 & 0.36 & $0.10-1.27$ & 0.114 & 0.50 & $0.27-0.94$ & 0.032 \\
\hline Intravenous drug addiction & 1.04 & $0.34-3.21$ & 0.941 & NC & & & 0.36 & $0.08-1.62$ & 0.183 \\
\hline \multicolumn{10}{|l|}{ Preexposure to antifungal drugs } \\
\hline Fluconazole & 2.42 & $1.63-3.59$ & $<0.0001$ & 6.17 & $3.44-11.07$ & $<0.0001$ & 1.03 & $0.58-1.85$ & 0.919 \\
\hline \multirow{3}{*}{ Echinocandins } & 3.45 & $1.88-6.33$ & $<0.0001$ & 3.70 & $1.40-9.80$ & 0.009 & 5.79 & $3.22-10.43$ & $<0.0001$ \\
\hline & \multicolumn{3}{|c|}{ C. tropicalis } & \multicolumn{3}{|c|}{ C. kefyr } & \multicolumn{3}{|c|}{ Multiple species } \\
\hline & OR & $95 \% \mathrm{Cl}$ & $p$ & OR & $95 \% \mathrm{Cl}$ & $p$ & OR & $95 \% \mathrm{Cl}$ & $p$ \\
\hline Male sex & 1.51 & $1.16-1.97$ & 0.002 & 0.90 & $0.52-1.55$ & 0.706 & 0.95 & $0.64-1.42$ & 0.812 \\
\hline \multicolumn{10}{|l|}{ Age (years) } \\
\hline$<45$ & 1 & & & 1 & & & 1 & & \\
\hline $45-64$ & 1.32 & $0.91-1.93$ & 0.143 & 1.84 & $0.72-4.73$ & 0.201 & 1.01 & $0.54-1.89$ & 0.963 \\
\hline $65-79$ & 1.14 & $0.95-2.10$ & 0.085 & 3.18 & $1.24-8.16$ & 0.016 & 1.11 & $0.58-2.12$ & 0.754 \\
\hline$\geq 80$ & 0.99 & $0.58-1.71$ & 0.982 & 0.77 & $0.15-4.07$ & 0.762 & 1.51 & $0.70-3.24$ & 0.289 \\
\hline ICU & 1.08 & $0.82-1.41$ & 0.594 & 1.56 & $0.88-2.78$ & 0.132 & 0.96 & $0.62-1.48$ & 0.839 \\
\hline Recent surgery (<30 days) & 0.83 & $0.62-1.10$ & 0.200 & 0.83 & $0.43-1.58$ & 0.567 & 0.96 & $0.63-1.47$ & 0.867 \\
\hline \multicolumn{10}{|l|}{ Underlying disease } \\
\hline No malignancy & 1 & & & 1 & & & 1 & & \\
\hline Digestive tumor & 0.73 & $0.47-1.14$ & 0.169 & 1.93 & $0.82-4.58$ & 0.134 & 1.52 & $0.85-2.69$ & 0.155 \\
\hline Other solid tumor & 0.98 & $0.68-1.43$ & 0.936 & 1.63 & $0.71-3.76$ & 0.248 & 1.70 & $1.00-2.90$ & 0.051 \\
\hline Acute leukemia & 4.16 & $2.58-6.70$ & $<0.0001$ & 12.36 & $5.15-29.64$ & $<0.0001$ & 0.82 & $0.24-2.83$ & 0.753 \\
\hline Lymphoma & 1.28 & $0.79-2.07$ & 0.318 & 2.55 & $0.93-7.00$ & 0.069 & 0.14 & $0.02-1.04$ & 0.055 \\
\hline Other hematological malignancy & 1.71 & $1.01-3.06$ & 0.044 & 1.31 & $0.28-6.04$ & 0.732 & 1.25 & $0.46-3.36$ & 0.663 \\
\hline Central venous catheter & 1.03 & $0.77-1.39$ & 0.822 & 0.75 & $0.40-1.41$ & 0.373 & 1.66 & $1.00-2.76$ & 0.052 \\
\hline HIV infection & 0.95 & $0.51-1.75$ & 0.857 & 0.46 & $0.59-3.61$ & 0.461 & 0.82 & $0.27-2.50$ & 0.730 \\
\hline Intravenous drug addiction & 1.74 & $0.56-5.41$ & 0.341 & NC & & & 8.31 & $2.82-24.49$ & $<0.0001$ \\
\hline \multicolumn{10}{|l|}{ Preexposure to antifungal drugs } \\
\hline Fluconazole & 1.14 & $0.63-2.08$ & 0.668 & 1.95 & $0.67-5.76$ & 0.223 & 0.50 & $0.12-2.08$ & 0.340 \\
\hline Echinocandins & 0.33 & $0.08-1.43$ & 0.137 & 2.74 & $0.75-10.09$ & 0.129 & 1.59 & $0.35-7.22$ & 0.551 \\
\hline
\end{tabular}

OR adjusted odd ratio for year, $95 \% \mathrm{Cl}$ odd ratio $95 \%$ confidence interval, $N \mathrm{C}$ non-calculable 
Table 3 Independent factors associated with death before day 8 or before day 30 in all adult patients with incident episode of fungemia due to single isolate of common Candida species (YEATS program, Paris area, 2002-2014)

\begin{tabular}{|c|c|c|c|c|c|c|c|c|}
\hline & \multicolumn{4}{|c|}{ Death before day $8^{a}$} & \multicolumn{4}{|c|}{ Death before day $30^{b}$} \\
\hline & $\mathrm{OR}^{\mathrm{c}}$ & $95 \% \mathrm{Cl}$ & & $p$ & $\mathrm{OR}^{\mathrm{c}}$ & $95 \% \mathrm{Cl}$ & & $p$ \\
\hline \multicolumn{9}{|l|}{ Age category (years) } \\
\hline$<45$ & 1 & & & & 1 & & & \\
\hline $45-64$ & 1.39 & $0.94-2.05$ & 0.101 & 0.0073 & 1.59 & $1.20-2.09$ & 0.001 & \\
\hline $65-79$ & 1.76 & $1.18-2.62$ & 0.005 & & 2.13 & $1.60-2.84$ & $<0.0001$ & $<0.0001$ \\
\hline$\geq 80$ & 2.11 & $1.30-3.41$ & 0.002 & & 2.92 & $2.05-4.15$ & $<0.0001$ & \\
\hline Hospitalization in ICU & 2.39 & $1.84-3.12$ & $<0.0001$ & & 2.47 & $2.03-3.01$ & $<0.0001$ & \\
\hline Recent surgery ( $\leq 30$ days) & 0.75 & $0.57-0.97$ & 0.031 & & 0.66 & $0.54-0.80$ & $<0.0001$ & \\
\hline \multicolumn{9}{|l|}{ Underlying disease } \\
\hline No malignancy & & & & & 1 & & & \\
\hline Digestive tumor & & & & & 1.42 & $1.08-1.85$ & 0.012 & \\
\hline Non-digestive tumor & & & & & 1.42 & $1.10-1.84$ & 0.007 & 0.00487 \\
\hline Acute leukemia & & & & & 1.06 & $0.70-1.62$ & 0.773 & \\
\hline Lymphoma & & & & & 1.25 & $0.88-1.78$ & 0.214 & \\
\hline Other hematological malignancy & & & & & 0.99 & $0.64-1.56$ & 0.982 & \\
\hline \multicolumn{9}{|l|}{ Species recovered from blood culture } \\
\hline C. albicans & 1 & & & & 1 & & & \\
\hline C. glabrata & 0.61 & $0.43-0.89$ & 0.009 & & 0.69 & $0.54-0.89$ & 0.004 & \\
\hline C.parapsilosis & 0.30 & $0.17-0.52$ & $<0.0001$ & $<0.0001$ & 0.49 & $0.35-0.67$ & $<0.0001$ & $<0.0001$ \\
\hline C. tropicalis & 1.00 & $0.67-1.49$ & 0.999 & & 1.00 & $0.74-1.34$ & 0.987 & \\
\hline C. krusei & 1.24 & $0.62-2.44$ & 0.544 & & 1.52 & $0.91-2.54$ & 0.106 & \\
\hline C. kefyr & 1.79 & $0.84-3.80$ & 0.132 & & 1.36 & $0.74-2.53$ & 0.325 & \\
\hline \multicolumn{9}{|l|}{ Initial antifungal treatment } \\
\hline Fluconazole alone & 1 & & & & 1 & & & \\
\hline Echinocandin alone & 1.02 & $0.74-1.41$ & 0.909 & $<0.0001$ & 1.08 & $0.86-1.36$ & 0.517 & $<0.0001$ \\
\hline Other treatments & 0.75 & $0.46-1.21$ & 0.234 & & 0.84 & $0.62-1.15$ & 0.283 & \\
\hline No antifungal drug & 10.96 & $7.60-15.81$ & $<0.0001$ & & 4.94 & $3.51-6.95$ & $<0.0001$ & \\
\hline
\end{tabular}

a Other variables included in full model (with $p<0.25$ in univariate analysis of early death) not conserved because not significant: allo-BMT, male gender, and type of underlying disease

b Male gender included in the model but not conserved because not significant

c OR adjusted for hospital and year (introduced in the model as dummy variable)

to those infected by C. albicans, patients with C. glabrata infections were more often very old, more often had digestive tumors, and were more often preexposed to echinocandins or fluconazole. These factors were also independently associated with death at day 30 . It is possible that the observation by others [41] that patients infected by C. glabrata have a higher crude mortality can be related to specificity of the cohort (249 patients with candidemia, 23 infected by C. glabrata) studied in several centers in 1992-1994 and to preexposure to antifungals, reflecting more severe cases as already described in the ICU population [42] rather than to the species itself. Evolution of patients' management may indeed at least partially explain the discrepant results.

Recent studies found that antifungal treatment was an independent factor decreasing both early and late death [31] and that echinocandins as first-line therapy reduced death rate [43]. As already reported [44] and shown here, a major observation is that a constant risk factor for death was the lack of antifungal prescription despite knowledge of the blood culture positivity, with no influence of the initial antifungal choice. In contrast to what is observed in the USA $[7,45]$, resistance to antifungals is not yet of concern in our area, with overall less than $1 \%$ resistance to caspofungin in isolates not identified as C. parapsilosis, less than $2.3 \%$ resistance to fluconazole in isolates not identified as C. krusei or C. glabrata, and no increase in these figures over time. Thus, we would recommend early prescription of antifungals based on the most likely species and the known susceptibility profile of its wild-type isolates rather than waiting for the precise identification and a fortiori for MIC determination. It may later be appropriate to switch to a more adapted treatment as recently validated in ICU [46]. 
The limitations of our database are the restriction to one city, the lack of information regarding severity of illness, the duration of candidemic period, central venous catheter removal [26], lack of consideration of antifungal dosing issues [47-49], and delayed initiation of adequate antifungal therapy $[47,50,51]$, concomitant mold infections, or bacteremia.

Even if we are fully aware that characteristics of candidemia are highly variable, especially in terms of species distribution, we think that our data are relevant for hematologists, oncologists, and ICU physicians practicing in the Western world. Indeed, characteristics and risk factors for death during candidemia differ in patients with hematological malignancies from those with solid tumors. Furthermore, the odds of infection by a given Candida species was influenced not only by host underlying disease but also by hopitalization in ICU and preexposure to antifungal drugs.

\section{Electronic supplementary material}

The online version of this article (doi:10.1007/s00134-017-4743-y) contains supplementary material, which is available to authorized users.

\section{Author details \\ ${ }^{1}$ Institut Pasteur, Molecular Mycology Unit, French National Reference Center for Invasive Mycoses and Antifungals, CNRS URA3012, 25, rue du Dr. Roux, 75724 Paris Cedex 15, France. ${ }^{2}$ Université Paris Descartes, Hôpital Necker-Enfants malades, Service des Maladies Infectieuses et Tropicales, Centre d'Infectiologie Necker-Pasteur, APHP, IHU Imagine, Paris, France. ${ }^{3}$ Labo- ratoire de Parasitologie-Mycologie, Hôpital Saint Louis, AP-HP, Université Paris Diderot, Paris, France.}

\section{Acknowledgements}

The following investigators participated in the YEASTS program of the French Mycosis Study Group: Collection of data in each participating center: C. Bouges-Michel, S. Brun (hôpital Avicenne, Bobigny), I. Poilane (hôpital Jean Verdier, Bondy), J. Dunan (hôpital Ambroise Paré, Boulogne), S. Bretagne, F. Botterel (hôpital Henri Mondor, Créteil), N. Fauchet (Centre Intercommunal, Créteil), E. Forget (hôpital Beaujon, Clichy), C. Lawrence (hôpital Raymond Poincaré, Garches), C. Bonnal, A. Angoulvant (hôpital du Kremlin Bicêtre, Kremlin-Bicêtre), O. Eloy (Centre Hospitalier, Le Chesnay), M.-F. David, N. Khassis, L. Milhaila (hôpital Paul Brousse, Villejuif), E. Chachaty (Institut Gustave Roussy, Villejuif), and in Paris: C. Chochillon (hôpital Bichat), A. Paugam, M.-T. Baixench (hôpital Cochin), M.-C. Escande (Institut Curie), M.-E. Bougnoux, Y. Sterckers, S. Challier (hôpital Necker), E. Dannaoui, V. Lavarde (hôpital Européen Georges Pompidou), A. Datry, B. Lmimouni, S. Brun, A. Fekkar (hôpital de la Pitié-Salpétrière), J.-L. Poirot (hôpital Saint Antoine), C. Lacroix, A. Alanio, S. Bretagne (hôpital Saint Louis), D. Moissenet (hôpital Trousseau), M. Develoux (hôpital Tenon), S. Bonacorsi (hôpital Robert Debré). Technical analysis of the isolates at the National Reference Center for Invasive Mycoses and Antifungals: Dea Garcia-Hermoso, Dorothée Raoux-Barbot, Damien Hoinard, Catherine Blanc, Anne Boullié.

\section{Compliance with ethical standards}

\section{Funding sources}

The YEASTS program was supported in part by Santé Publique France and Institut Pasteur. The funders had no role in study design, data collection, analysis, or interpretation of data.

\section{Ethics committee approval}

The research described herein was carried out in compliance with French law and the Declaration of Helsinki (as adopted in 2000), and was approved by the Institut Pasteur institutional review board (IRB \#2009-34). Approval of the
"Commission Nationale de l'Informatique et des Libertés" was obtained, ensuring that patients' data were kept anonymous according to French regulations.

\section{Open Access}

This article is distributed under the terms of the Creative Commons Attribution-NonCommercial 4.0 International License (http://creativecommons.org/ licenses/by-nc/4.0/), which permits any noncommercial use, distribution, and reproduction in any medium, provided you give appropriate credit to the original author(s) and the source, provide a link to the Creative Commons license, and indicate if changes were made.

Received: 7 October 2016 Accepted: 23 February 2017

Published online: 20 March 2017

\section{References}

1. Marchetti O, Bille J, Fluckiger U, Eggimann P, Ruef C, Garbino J, Calandra T, Glauser MP, Tauber MG, Pittet D, Fungal Infection Network of Switzerland (2004) Epidemiology of candidemia in Swiss tertiary care hospitals: secular trends, 1991-2000. Clin Infect Dis 38:311-320

2. Marra AR, Camargo LF, Pignatari AC, SukiennikT, Behar PR, Medeiros EA, Ribeiro J, Girao E, Correa L, Guerra C, Brites C, Pereira CA, Carneiro I, Reis M, de Souza MA, Tranchesi R, Barata CU, Edmond MB, Brazilian SCOPE Study Group (2011) Nosocomial bloodstream infections in Brazilian hospitals: analysis of 2563 cases from a prospective nationwide surveillance study. J Clin Microbiol 49:1866-1871

3. Wisplinghoff $H$, Bischoff T, Tallent SM, Seifert $H$, Wenzel RP, Edmond MB (2004) Nosocomial bloodstream infections in US hospitals: analysis of 24,179 cases from a prospective nationwide surveillance study. Clin Infect Dis 39:309-317

4. Zaoutis TE, Argon J, Chu J, Berlin JA, Walsh TJ, Feudtner C (2005) The epidemiology and attributable outcomes of candidemia in adults and children hospitalized in the United States: a propensity analysis. Clin Infect Dis 41:1232-1239

5. Pfaller MA, Diekema DJ (2007) Epidemiology of invasive candidiasis: a persistent public health problem. Clin Microbiol Rev 20:133-163

6. Arendrup MC, Sulim S, Holm A, Nielsen L, Nielsen SD, Knudsen JD, Drenck NE, Christensen JJ, Johansen HK (2011) Diagnostic issues, clinical characteristics, and outcomes for patients with fungemia. J Clin Microbiol 49:3300-3308

7. Pfaller M, Neofytos D, Diekema D, Azie N, Meier-Kriesche HU, Quan SP, Horn D (2012) Epidemiology and outcomes of candidemia in 3648 patients: data from the prospective antifungal therapy [PATH Alliance(R)] registry, 2004-2008. Diagn Microbiol Infect Dis 74:323-331

8. Arendrup MC, Dzajic E, Jensen $\mathrm{RH}$, Johansen HK, Kjaeldgaard P, Knudsen JD, Kristensen L, Leitz C, Lemming LE, Nielsen L, Olesen B, Rosenvinge FS, Roder BL, Schonheyder HC (2013) Epidemiological changes with potential implication for antifungal prescription recommendations for fungaemia: data from a nationwide fungaemia surveillance programme. Clin Microbiol Infect 19:E343-353

9. Lortholary O, Renaudat C, Sitbon K, Madec Y, Denoeud-Ndam L, Wolff M, Fontanet A, Bretagne S, Dromer F, French Mycosis Study Group (2014) Worrisome trends in incidence and mortality of candidemia in intensive care units (Paris area, 2002-2010). Intensive Care Med 40:1303-1312

10. Kuse ER, Chetchotisakd P, da Cunha CA, Ruhnke M, Barrios C, Raghunadharao D, Sekhon JS, Freire A, Ramasubramanian V, Demeyer I, Nucci M, Leelarasamee A, Jacobs F, Decruyenaere J, Pittet D, Ullmann AJ, OstroskyZeichner L, Lortholary O, Koblinger S, Diekmann-Berndt H, Cornely OA, Micafungin Invasive Candidiasis Working Group (2007) Micafungin versus liposomal amphotericin B for candidaemia and invasive candidosis: a phase III randomised double-blind trial. Lancet 369:1519-1527

11. Mora-Duarte J, Betts R, Rotstein C, Colombo AL, Thompson-Moya L, Smietana J, Lupinacci R, Sable C, Kartsonis N, Perfect J, Caspofungin Invasive Candidiasis Study Group (2002) Comparison of caspofungin and amphotericin B for invasive candidiasis. N Engl J Med 347:2020-2029

12. Reboli AC, Rotstein C, Pappas PG, Chapman SW, Kett DH, Kumar D, Betts R, Wible M, Goldstein BP, Schranz J, Krause DS, Walsh TJ, Anidulafungin Study Group (2007) Anidulafungin versus fluconazole for invasive candidiasis. N Engl J Med 356:2472-2482 
13. Cornely OA, Bassetti M, Calandra T, Garbino J, Kullberg BJ, Lortholary O, Meersseman W, Akova M, Arendrup MC, Arikan-Akdagli S, Bille J, Castagnola E, Cuenca-Estrella M, Donnelly JP, Groll AH, Herbrecht R, Hope WW, Jensen HE, Lass-Florl C, Petrikkos G, Richardson MD, Roilides E, Verweij PE, Viscoli C, Ullmann AJ, ESCMID Fungal Infection Study Group (2012) ESCMID guideline for the diagnosis and management of Candida diseases 2012: non-neutropenic adult patients. Clin Microbiol Infect 18(Suppl 7):19-37

14. Pappas PG, Kauffman CA, Andes D, Benjamin DK Jr, Calandra TF, Edwards JE Jr, Filler SG, Fisher JF, Kullberg BJ, Ostrosky-Zeichner L, Reboli AC, Rex $\mathrm{JH}$, Walsh TJ, Sobel JD, Infectious Diseases Society of America (2009) Clinical practice guidelines for the management of candidiasis: 2009 update by the Infectious Diseases Society of America. Clin Infect Dis 48:503-535

15. Sabino R, Verissimo C, Brandao J, Alves C, Parada H, Rosado L, Paixao E, Videira Z, Tendeiro T, Sampaio P, Pais C (2010) Epidemiology of candidemia in oncology patients: a 6-year survey in a Portuguese central hospital. Med Mycol 48:346-354

16. Sipsas NV, Lewis RE, Tarrand J, Hachem R, Rolston KV, Raad II, Kontoyiannis DP (2009) Candidemia in patients with hematologic malignancies in the era of new antifungal agents (2001-2007): stable incidence but changing epidemiology of a still frequently lethal infection. Cancer 115:4745-4752

17. Zirkel J, Klinker H, Kuhn A, Abele-Horn M, Tappe D, Turnwald D, Einsele H, Heinz WJ (2012) Epidemiology of Candida blood stream infections in patients with hematological malignancies or solid tumors. Med Mycol 50:50-55

18. Gamaletsou MN, Walsh TJ, Zaoutis T, Pagoni M, Kotsopoulou M, Voulgarelis M, Panayiotidis P, Vassilakopoulos T, Angelopoulou MK, Marangos M, Spyridonidis A, Kofteridis D, Pouli A, Sotiropoulos D, Matsouka P, Argyropoulou A, Perloretzou S, Leckerman K, Manaka A, Oikonomopoulos P, Daikos G, Petrikkos G, Sipsas NV (2014) A prospective, cohort, multicentre study of candidaemia in hospitalized adult patients with haematological malignancies. Clin Microbiol Infect 20:050-57

19. Cornely OA, Gachot B, Akan H, Bassetti M, Uzun O, Kibbler C, Marchetti O, de Burghgraeve P, Ramadan S, Pylkkanen L, Ameye L, Paesmans M, Donnelly JP, EORTC Infectious Diseases Group (2015) Epidemiology and outcome of fungemia in a cancer cohort of the Infectious Diseases Group (IDG) of the European Organization for Research and Treatment of Cancer (EORTC 65031). Clin Infect Dis 61:324-331

20. Lortholary O, Desnos-Ollivier M, Sitbon K, Renaudat C, Bretagne S, Dromer $F$ (2016) Characteristics of candidemia in oncology differ from those in hematology: a prospective study over a decade. Poster presented at 26th ECCMID, Amsterdam, the Netherlands

21. Bretagne S, Renaudat C, Desnos-Ollivier M, Sitbon K, Lortholary O, Dromer F, on behalf of the French Mycosis Study Group (2017) Predisposing factors and outcome of uncommon yeast species-related fungaemia based on an exhaustive surveillance programme (2002-14). J Antimicrob Chemother. doi:10.1093/jac/dkx045

22. Lortholary O, Desnos-Ollivier M, Sitbon K, Fontanet A, Bretagne S, Dromer F, French Mycosis Study Group (2011) Recent exposure to caspofungin or fluconazole influences the epidemiology of candidemia: a prospective multicenter study involving 2,441 patients. Antimicrob Agents Chemother 55:532-538

23. Arendrup MC, Guinea J, Cuenca-Estrella M, Meletiadis J, Mouton JW, Lagrou K, Howard SJ, EUCAST-AFST (2015) EUCAST technical note on the EUCAST definitive document EDef 7.3: method for the determination of broth dilution minimum inhibitory concentrations of antifungal agents for yeasts. http://www.eucast.org. Accessed Feb 2017.

24. European Committee on Antibiotic Susceptibility Testing (2013) Fluconazole: rationale for the clinical breakpoints, version 2.0. http://www.eucast. org. Accessed Feb 2017.

25. Desnos-Ollivier M, Bretagne S, Raoux D, Hoinard D, Dromer F, Dannaoui E, European Committee on Antibiotic Susceptibility Testing (2008) Mutations in the fks1 gene in Candida albicans, C. tropicalis, and C. krusei correlate with elevated caspofungin MICs uncovered in AM3 medium using the method of the European Committee on Antibiotic Susceptibility Testing. Antimicrob Agents Chemother 52:3092-3098

26. Puig-Asensio M, Padilla B, Garnacho-Montero J, Zaragoza O, Aguado JM, Zaragoza R, Montejo M, Munoz P, Ruiz-Camps I, Cuenca-Estrella M, Almirante B, CANDIPOP, GEIH-GEMICOMED (SEIMC), REIPI (2014) Epidemiology and predictive factors for early and late mortality in Candida bloodstream infections: a population-based surveillance in Spain. Clin Microbiol Infect 20:0245-254

27. Kontoyiannis DP, Marr KA, Park BJ, Alexander BD, Anaissie EJ, Walsh TJ, Ito J, Andes DR, Baddley JW, Brown JM, Brumble LM, Freifeld AG, Hadley S, Herwaldt LA, Kauffman CA, Knapp K, Lyon GM, Morrison VA, Papanicolaou G, Patterson TF, Perl TM, Schuster MG, Walker R, Wannemuehler KA, Wingard JR, Chiller TM, Pappas PG (2010) Prospective surveillance for invasive fungal infections in hematopoietic stem cell transplant recipients, 2001-2006: overview of the Transplant-Associated Infection Surveillance Network (TRANSNET) Database. Clin Infect Dis 50:1091-1100

28. Chen CY, Huang SY, Tsay W, Yao M, Tang JL, Ko BS, Chou WC, Tien HF, Hsueh PR (2012) Clinical characteristics of candidaemia in adults with haematological malignancy, and antimicrobial susceptibilities of the isolates at a medical centre in Taiwan, 2001-2010. Int J Antimicrob Agents 40:533-538

29. Pagano L, Caira M, Candoni A, Offidani M, Fianchi L, Martino B, Pastore D, Picardi M, Bonini A, Chierichini A, Fanci R, Caramatti C, Invernizzi R, Mattei D, Mitra ME, Melillo L, Aversa F, Van Lint MT, Falcucci P, Valentini CG, Girmenia C, Nosari A (2006) The epidemiology of fungal infections in patients with hematologic malignancies: the SEIFEM-2004 study. Haematologica 91:1068-1075

30. Bitar D, Lortholary O, Le Strat Y, Nicolau J, Coignard B, Tattevin P, Che D, Dromer $F$ (2014) Population-based analysis of invasive fungal infections, France, 2001-2010. Emerg Infect Dis 20:1149-1155

31. Almirante B, Rodriguez D, Park BJ, Cuenca-Estrella M, Planes AM, Almela M, Mensa J, Sanchez F, Ayats J, Gimenez M, Saballs P, Fridkin SK, Morgan J, Rodriguez-Tudela JL, Warnock DW, Pahissa A, Barcelona Candidemia Project Study Group (2005) Epidemiology and predictors of mortality in cases of Candida bloodstream infection: results from populationbased surveillance, barcelona, Spain, from 2002 to 2003. J Clin Microbiol 43:1829-1835

32. Hachem R, Hanna H, Kontoyiannis D, Jiang Y, Raad I (2008) The changing epidemiology of invasive candidiasis: Candida glabrata and Candida krusei as the leading causes of candidemia in hematologic malignancy. Cancer 112:2493-2499

33. Horn DL, Neofytos D, Anaissie EJ, Fishman JA, Steinbach WJ, Olyaei AJ, Marr KA, Pfaller MA, Chang CH, Webster KM (2009) Epidemiology and outcomes of candidemia in 2019 patients: data from the prospective antifungal therapy alliance registry. Clin Infect Dis 48:1695-1703

34. Munoz P, Giannella M, Fanciulli C, Guinea J, Valerio M, Rojas L, RodriguezCreixems M, Bouza E (2011) Candida tropicalis fungaemia: incidence, risk factors and mortality in a general hospital. Clin Microbiol Infect 17:1538-1545

35. Dufresne SF, Marr KA, Sydnor E, Staab JF, Karp JE, Lu K, Zhang SX, Lavallee C, Perl TM, Neofytos D (2014) Epidemiology of Candida kefyr in patients with hematologic malignancies. J Clin Microbiol 52:1830-1837

36. Nace HL, Horn D, Neofytos D (2009) Epidemiology and outcome of multiple-species candidemia at a tertiary care center between 2004 and 2007. Diagn Microbiol Infect Dis 64:289-294

37. Chow JK, Golan Y, Ruthazer R, Karchmer AW, Carmeli Y, Lichtenberg D, Chawla V, Young J, Hadley S (2008) Factors associated with candidemia caused by non-albicans Candida species versus Candida albicans in the intensive care unit. Clin Infect Dis 46:1206-1213

38. Rodriguez D, Almirante B, Cuenca-Estrella M, Rodriguez-Tudela JL, Mensa J, Ayats J, Sanchez F, Pahissa A, Barcelona Candidemia Project Study Group (2010) Predictors of candidaemia caused by non-albicans Candida species: results of a population-based surveillance in Barcelona, Spain. Clin Microbiol Infect 16:1676-1682

39. Schuster MG, Meibohm A, Lloyd L, Strom B (2013) Risk factors and outcomes of Candida krusei bloodstream infection: a matched, case-control study. J Infect 66:278-284

40. Slavin MA, Sorrell TC, Marriott D, Thursky KA, Nguyen Q, Ellis DH, Morrissey CO, Chen SC, Australian Candidemia Study, Australasian Society for Infectious Diseases (2010) Candidaemia in adult cancer patients: risks for fluconazole-resistant isolates and death. J Antimicrob Chemother 65:1042-1051

41. Viscoli C, Girmenia C, Marinus A, Collette L, Martino P, Vandercam B, Doyen C, Lebeau B, Spence D, Krcmery V, De Pauw B, Meunier F (1999) Candidemia in cancer patients: a prospective, multicenter surveillance study by the Invasive Fungal Infection Group (IFIG) of the European 
Organization for Research and Treatment of Cancer (EORTC). Clin Infect Dis 28:1071-1079

42. Leroy O, Bailly S, Gangneux JP, Mira JP, Devos P, Dupont H, Montravers P, Perrigault PF, Constantin JM, Guillemot D, Azoulay E, Lortholary O, Bensoussan C, Timsit JF, Csg Amar (2016) Systemic antifungal therapy for proven or suspected invasive candidiasis: the AmarCAND 2 study. Ann Intensive Care 6:2

43. Andes DR, Safdar N, Baddley JW, Playford G, Reboli AC, Rex JH, Sobel JD, Pappas PG, Kullberg BJ, Mycoses Study Group (2012) Impact of treatment strategy on outcomes in patients with candidemia and other forms of invasive candidiasis: a patient-level quantitative review of randomized trials. Clin Infect Dis 54:1110-1122

44. Tang HJ, Liu WL, Lin HL, Lai CC (2014) Epidemiology and prognostic factors of candidemia in cancer patients. PLoS One 9:e99103

45. Cleveland AA, Farley MM, Harrison LH, Stein B, Hollick R, Lockhart SR, Magill SS, Derado G, Park BJ, Chiller TM (2012) Changes in incidence and antifungal drug resistance in candidemia: results from population-based laboratory surveillance in Atlanta and Baltimore, 2008-2011. Clin Infect Dis 55:1352-1361

46. Bailly S, Leroy O, Montravers $\mathrm{P}$, Constantin JM, Dupont $\mathrm{H}$, Guillemot D, Lortholary O, Mira JP, Perrigault PF, Gangneux JP, Azoulay E, Timsit JJ (2015) Antifungal de-escalation was not associated with adverse outcome in critically ill patients treated for invasive candidiasis: post hoc analyses of the AmarCAND2 study data. Intensive Care Med 41:1931-1940
47. Zilberberg MD, Kollef MH, Arnold H, Labelle A, Micek ST, Kothari S, Shorr AF (2010) Inappropriate empiric antifungal therapy for candidemia in the ICU and hospital resource utilization: a retrospective cohort study. BMC Infect Dis 10:150

48. Labelle AJ, Micek ST, Roubinian N, Kollef MH (2008) Treatment-related risk factors for hospital mortality in Candida bloodstream infections. Crit Care Med 36:2967-2972

49. Pai MP, Turpin RS, Garey KW (2007) Association of fluconazole area under the concentration-time curve/MIC and dose/MIC ratios with mortality in nonneutropenic patients with candidemia. Antimicrob Agents Chemother 51:35-39

50. Kollef M, Micek S, Hampton N, Doherty JA, Kumar A (2012) Septic shock attributed to Candida infection: importance of empiric therapy and source control. Clin Infect Dis 54:1739-1746

51. Garey KW, Rege M, Pai MP, Mingo DE, Suda KJ, Turpin RS, Bearden DT (2006) Time to initiation of fluconazole therapy impacts mortality in patients with candidemia: a multi-institutional study. Clin Infect Dis 43:25-31 